\title{
ANÁLISE DAS VARIAÇÕES NO LUCRO LIQQUIDO
}

* Ivan Pinto Dias

\begin{abstract}
A análise vertical e horizontal da Demonstração de Resultado do Exercício pode ser descomplicada.
\end{abstract}

The vertical and horizontal analysis of Income Statement can be easy.

PALAVRAS-CHAVE:

Análise vertical e horizontal, Demonstração de Resultados do Exercício, lucro líquido, inflação, Demonstração das Variaçōes no Lucro Líquido.

\section{KEY WORDS:}

Vertical and horizontal analysis, Income Statement, Net Income, inflation, Statement of Changes in Net Income.
* Professor Titular do Departamento de Contabilidade, Finanças e Controle da EAESP/FGV.

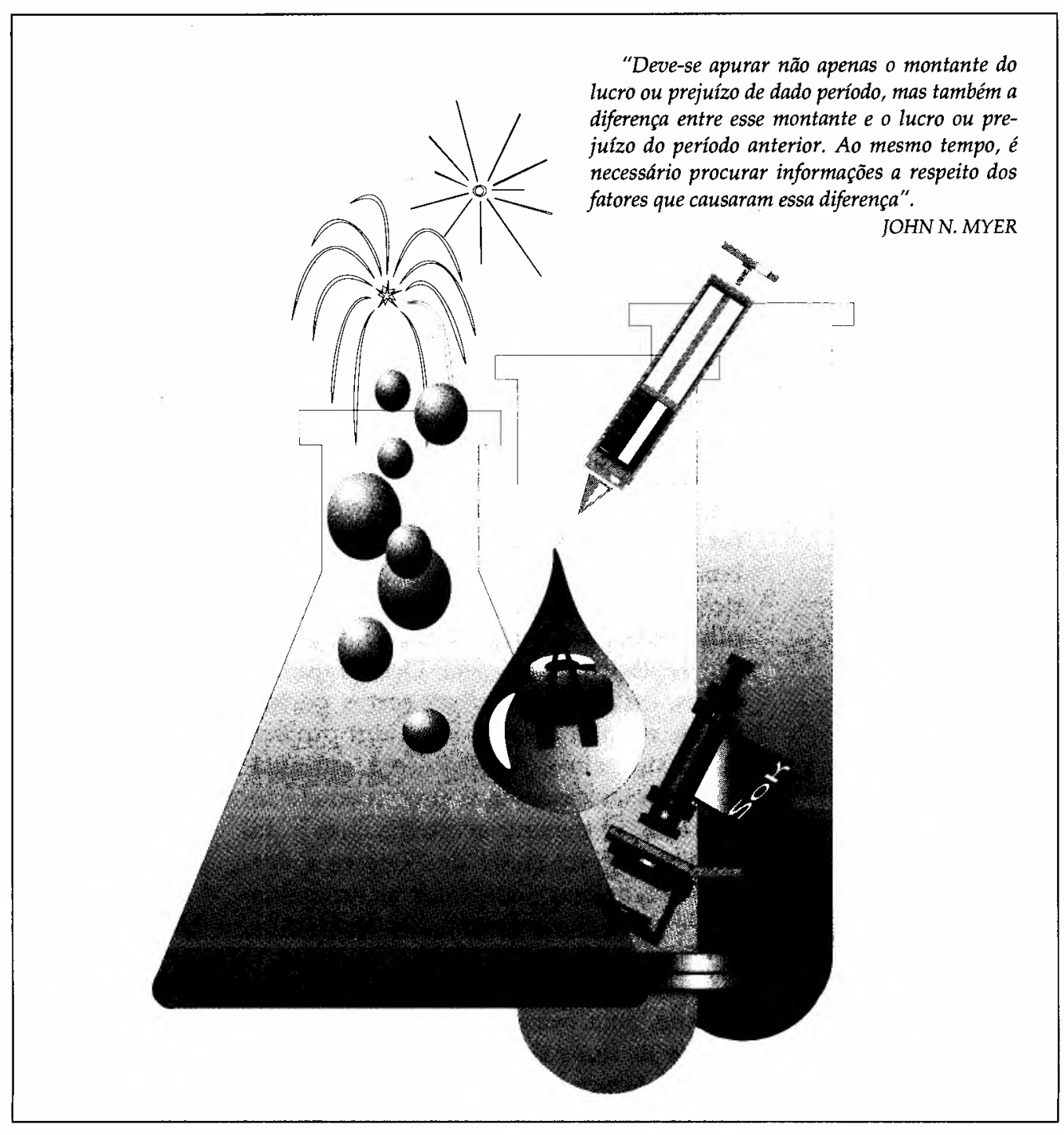


Ao analisar as demonstraçōes financeiras das empresas, os autores modernos no campo da Administração Contábil e Financeira têm - muito acertadamente e por várias razões - quase à unanimidade emprestado ênfase maior à demonstração da conta de "Lucros e Perdas" do que ao balanço. A primeira seria como um filme cinematográfico que mostrasse o que aconteceu com a empresa durante um dado exercício, enquanto que o último é apenas - completando a analogia - uma fotografia instantânea da firma em determinado dia.

\section{Na análise vertical, toma-se}

o total das vendas líquidas

como base para o cálculo de

\section{percentagem e verifica-se}

quanto, percentualmente,

cada item da demonstração

representa desse total.

Isso não significa que o balanço e sua análise não devam ser levados em consideração. Porém, nāo há dúvida de que, se for dado assistir a um filme - desde que bom -, sairemos muito melhor informados sobre qualquer assunto do que se olharmos para uma simples fotografia, por melhor que ela seja. Ocorre que, às vezes, ou desejamos fixar certos pormenores, ou não dispomos de um projetor cinematográfico. A opção será, em qualquer desses casos, usar unicamente a fotografia. O mesmo acontece com a demonstração da conta de "Lucros e Perdas" e o balanço: conforme as necessidades e os instrumentos que tenhamos, analisaremos uma ou outro.

Naturalmente, é sempre de bom alvitre que, uma vez interpretadas separadamente as duas demonstrações financeiras, juntemos as duas análises feitas, a fim de chegar a conclusões finais sobre a situação econômico-financeira da empresa. Por essa razão, a expressão "análise de balanços" - que, com pequenas variações, é muito difundida no Brasil e tem sido objeto da atenção de autores patrícios - já foi abandonada, em outros países, em favor da expressão "análise das demonstrações financeiras", que tem a virtude de esclarecer que não só o balanço é importante, mas também a demonstração da conta de "Lucros e Perdas".

Neste artigo apresentaremos diversas formas de analisar a demonstração da conta de "Lucros e Perdas" e, mais especificamente, de conhecer as razões das variaçōes no lucro líquido de um período contábil para outro. Partiremos da hipótese de que estamos dentro de uma empresa e conhecemos todos os fatos sobre ela. A demonstração da conta de "Lucros e Perdas" a que nos referiremos é a utilizada internamente nas empresas com informaçōes sobre vendas, custo das mercadorias vendidas etc., portanto, bem diferente das demonstrações que geralmente são publicadas nos jornais e infelizmente mais confundem o leitor - em especial o leigo - do que o esclarecem.

Utilizaremos quantias e proporções arredondadas e aproximadas, que não espelham necessariamente a realidade, pois estamos interessados em princípios e estes poderão melhor ser entendidos se trabalharmos com exemplos numéricos de fácil compreensão.

Alguns dos tipos de demonstraçŏes e análises a serem aqui apresentados poderão ser encontrados em livros ou em revistas especializadas, publicados em outros idiomas, principalmente no inglês. Embora não pretendamos ser inteiramente originais, nossa contribuição tem o sentido de adaptar os conhecimentos acumulados em outros países sobre o assunto às condições nacionais e permitir ao administrador brasileiro a possibilidade de ter mais um instrumento de trabatho à sua disposição.

\section{CASO DA COMPANHIA ALFA}

Para clareza de exposição, vamos supor a existência de uma empresa, Companhia Alfa, cuja demonstração da conta de "Lucros e Perdas" seja a resumida no quadro 1. 
Observe-se que nesse resumo o lucro líquido operacional seria aquele resultante das operações normais da empresa. Não é esse o significado de lucro líquido operacional adotado pela nossa legislação fiscal. No caso em questão foi suposta a inexistência de outras reccitas (inclusive receitas financeiras), as quais não entrariam no computo do lucro líquido operacional, mas na apuração do lucro líquido do período, isto é, estariam na posição em que estão colocadas as outras despesas - e despesas financeiras - (algumas empresas consideram - a nosso ver erroneamente - as despesas financeiras como parte integrante das despesas operacionais).

A classificação dada para as despesas operacionais poderá ser ampliada, conforme o tipo de empresa, o plano de contas da empresa etc. Poderia ter sido feito o cálculo do imposto sobre a renda, o qual seria então subtraído do lucro líquido do período e, teria, naturalmente, sua contrapartida no balanço (Imposto de Renda Estimado a Pagar, Provisão para o Imposto de Renda etc). No caso de uma sociedade anônima, é preferivel não mostrar, num resumo como o que apresentamos, a apropriação do lucro para as várias reservas e para o pagamento de dividendos, assim como o saldo não distribuído que permaneceria para o próximo exercício (lucros retidos). A apropriação do lucro do período deve, de preferência, aparecer à parte, na demonstração de "Lucros e Retidos".

Ao analisar o quadro 1, logo à primeira vista percebemos que, comparando-se aos anos de $19 \times 2$ e 19x1, houve um aumento nas vendas líquidas e, no entanto, o lucro bruto sobre as vendas, quando o lucro líquido operacional e o lucro líquido do período diminuíram. Nota-se, também, que somente as despesas administrativas e as outras despesas (inclusive financeiras) é que sofreram redução de um período para outro.

Essa análise superficial, porém, deve ser imediatamente completada por uma análise cuidadosa e completa de todos os anexos a essas demonstrações, onde serẫo encontradas todas as informações minuciosas sobre vendas, custo das mercadorias vendidas e despesas. Analisando-se csses anexos, por exemplo, pode-

\section{Quadro 1: Resumo da Demonstração de "Lucros e Perdas" (em milhares de cruzeiros)}

\begin{tabular}{|c|c|c|c|c|}
\hline \multirow[b]{2}{*}{ 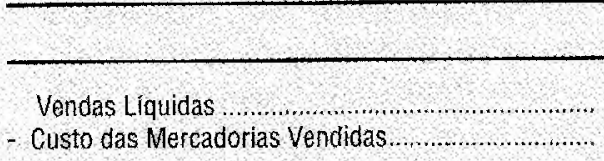 } & \multicolumn{2}{|c|}{$19 \times 1$} & \multicolumn{2}{|c|}{$19 \times 2$} \\
\hline & $\operatorname{cr} \$$ & $\begin{array}{r}1.000 \\
400\end{array}$ & $\cos$ & $\begin{array}{l}1.500 \\
1.000\end{array}$ \\
\hline Lucro Bruto sobre Vendas . & $\cos$ & 600 & Cr\$ & 500 \\
\hline 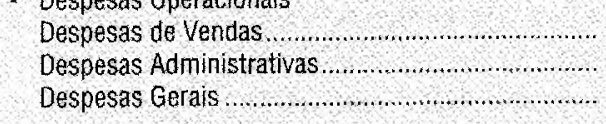 & Crs & $\begin{array}{l}100 \\
100 \\
100\end{array}$ & $\operatorname{Cr} \$$ & $\begin{array}{r}200 \\
50 \\
150\end{array}$ \\
\hline Total de Despesas Dperacionais ............................ & $\operatorname{cr} \$$ & 300 & $\mathrm{Cr} \$$ & 400 \\
\hline $\begin{array}{l}\text { Lucro Liquido Operacional ................................. } \\
\text { - Outras Despesas (e Despesas Financeiras) }\end{array}$ & $\mathrm{Cr} \$$ & $\begin{array}{l}300 \\
100\end{array}$ & $\operatorname{crs}$ & $\begin{array}{r}100 \\
10\end{array}$ \\
\hline Lucro Liquido no Períado .......... & $\operatorname{crs}$ & 200 & $\operatorname{cr} \$$ & 90 \\
\hline
\end{tabular}

se chegar a uma primeira conclusão: a de que a situação do lucro líquido do período de $19 \times 2$ é pior, quando comparada à de $19 \times 1$, do que parecia à primeira vista, pois, no primeiro ano, sob o item "Outras Despesas (e Despesas Financeiras)", cujo total era de Cr\$ 100.000 , estavam incluídos Cr $\$ 80.000$ de prejuízo resultante da venda de um ativo fixo; portanto, se isso não tivesse acontecido, o lucro líquido em $19 \times 1$ seria de Cr $\$ 280.000$ (Cr\$200.000+Cr\$ 80.000 ). Ora, como não acontece todos os anos esse tipo de transação - venda de ativo fixo e com prejuízo - o lucro líquido do período de $19 \times 2$ está muito abaixo do lucro líquido de $19 \times 1$ que poderíamos chamar normal, isto é, expurgado do prejuízo de Cr $\$ 80.000 .{ }^{1}$

Antes de passar à análise cuidadosa dos anexos às demonstrações - passo que deixaremos para o final a fim de não ficarmos assoberbados por nomes de contas e respectivas importâncias, perdendo a visão global proporcional pelo resumo das operações mostrado no quadro 1 - é necessário descobrir o porquê da variação no lucro líquido do período de um ano para outro. Uma das formas de fazê-lo vem discutida a seguir.

\section{ANÁLISE VERTICAL E HORIZONTAL}

$\mathrm{Na}$ análise vertical toma-se o total das vendas líquidas como base para o cálculo de percentagem e verifica-se quanto, percentualmente, cada item da
1. 0 leitor pode raciocinar para todas as quantias mencionadas neste artigo em termos de qualquer unidade monetária, isto as tornará muito mais significativas e próximas da realidade. 
2. As percentagens e os indices

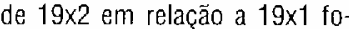
ram arredondados para a casa decimal mais próxima. É obvio, portanto, que as outras despesas (e despesas financeiras) do ano de $19 \times 2$. no valor de $\mathrm{Cr} \$$ 10.000 , não podem ser $1 \%$ das vendas líquidas do mesmo ano (Cr\$1.500.000), mas apenas $0.667 \%$ das mesmas. Para nossas finalidades esse arredonda mento não é prejudicial, também na vida prática, conforme a exatidão desejada, é melhor e mais fácil trabalhar com números arredondados. Por exemplo, quando se fala em $26,85 \%$ de alguma coisa, fica na memória do ouvinte mais facilmente 0 número 85 do que o número 25. Portanto, por que não dizer logo que se trata de $27 \%$ de algo? demonstração representa desse total. Ao mesmo tempo, na análise horizontal, determina-se qual a variação das quantias monetárias de um exercício para outro c a percentagem dessa variação. Ao lado dessas últimas percentagens, é interessante ter também o índice de um período em relação a outro pois quando as alteraçôes percentuais são muito elevadas, é, às vezes, um pouco difícil interpretá-las. É mais fácil, por exemplo, compreender que uma quantia representa dez vezes uma outra do que entender que a mesma é $900 \%$ maior que a outra.

O quadro 2 mostra a análise vertical e horizontal do resumo da demonstração da conta de "Lucros e Perdas" da cmpresa Alfa.

O quadro 2 indica que as vendas líquidas em 19x2 aumentaram em 50\%, enquanto que os custos, das mercadorias vendidas se clevou em $150 \%$ (ou é igual a 2,5 vezes, conforme se vê na coluna dos índices de $19 \times 2$, em relação a $19 \times 1)$. Isso resultou, portanto, numa diminuição de $17 \%$ no lucro bruto sobre vendas, uma vez que este representa $60 \%$ das vendas em $19 \times 1$ e em $19 \times 2$ representa apenas $33 \%$, ou seja, o lucro bruto sobre vendas de $19 \times 2$ representa apenas 0,8 vezes o de $19 \times 1$.
Tanto as despesas de vendas como as despesas gerais aumentaram em 19x2, pois as primeiras, que representavam $10 \%$ das vendas líquidas em $19 \times 1$, importam agora em $13 \%$, ou, ainda, são em $19 \times 2$ duas vezes as despesas de vendas de $19 \times 1$. (Houve, portanto, um aumento de $100 \%$.) Por sua vez, as despesas gerais, embora continuem representando $10 \%$ das vendas líquidas nos dois anos e essas aumentaram em 50\% de um exercício para outro -, elevaram-se cm $50 \%$ no ano de $19 \times 2$, isto é, são iguais a 1,5 vezes as de $19 \times 1$.

Por outro lado, houve diminuição nas despesas administrativas e nas outras despesas (inclusive financeiras), as quais são em $19 \times 250 \%$ e $90 \%$ respectivamente mais baixas do que as de $19 \times 1$, ou seja, 0,5 e 0,1 vezes, respectivamente. (Ver coluna dos índices de $19 \times 2$ em relação a 19x1.)

Nota-se que essas diminuições são muito pequenas, tanto em valores relativos quanto em valores absolutos, quando comparadas, por exemplo, com o aumento de Cr\$ 600.000 (150\%) no custo das mercadorias vendidas, custo que é em 19x2 2,5 vezes o de $19 \times 1$.

Portanto, mesmo ocorrendo a redução nas despesas administrativas em relação às vendas líquidas (de $10 \%$ em 19) 1 di-

\begin{tabular}{|c|c|c|c|c|c|c|c|c|c|c|}
\hline \multicolumn{11}{|c|}{$\begin{array}{l}\text { QUADRO 2: Análise Vertical e Horizontal do Resumo da Demonstração da Conta de Lucros e Perdas }{ }^{2} \\
\text { (em milhares de cruzeiros) }\end{array}$} \\
\hline & \multicolumn{3}{|c|}{$19 \times 1$} & \multicolumn{3}{|c|}{$19 \times 2$} & \multicolumn{2}{|c|}{$\begin{array}{l}\text { Aumento } \\
\text { (ou } \\
\text { Diminuição) }\end{array}$} & \multirow{2}{*}{$\begin{array}{c}\begin{array}{c}\text { Aumento } \\
\text { (ou } \\
\text { Diminuição } \\
\text { em \%) }\end{array} \\
50 \% \\
150\end{array}$} & \multirow{2}{*}{$\begin{array}{c}\begin{array}{c}\text { Indice de } \\
19 \times 2 \text { em } \\
\text { relação } \\
\text { a 19x1 }\end{array} \\
1,5 \\
2,5\end{array}$} \\
\hline 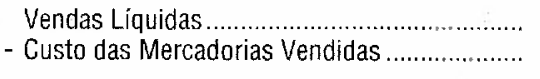 & & $\begin{array}{r}1.000 \\
400\end{array}$ & $\begin{array}{c}100 \% \\
40\end{array}$ & $\mathrm{Cr} \$$ & $\begin{array}{l}1.500 \\
1.000\end{array}$ & $\begin{array}{c}100 \% \\
67\end{array}$ & $\operatorname{crs}$ & $\begin{array}{l}500 \\
600\end{array}$ & & \\
\hline 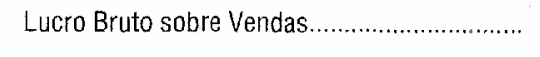 & $\mathrm{Cr}$ & 600 & $60 \%$ & $\mathrm{Cr} \$$ & 500 & $33 \%$ & $(\mathrm{Cr} \$$ & 100) & $(17 \%)$ & 0,8 \\
\hline 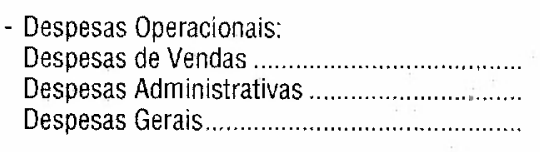 & $\mathrm{Cr} \$$ & $\begin{array}{l}100 \\
100 \\
100 \\
\end{array}$ & $\begin{array}{l}10 \% \\
10 \\
10\end{array}$ & $\mathrm{Cr} \$$ & $\begin{array}{r}200 \\
50 \\
150 \\
\end{array}$ & $\begin{array}{l}13 \% \\
3 \\
10\end{array}$ & $\operatorname{Cr} \$$ & $\begin{array}{r}100 \\
(50) \\
50\end{array}$ & $\begin{array}{l}100 \% \\
(50) \\
50\end{array}$ & $\begin{array}{l}2,0 \\
0,5 \\
1,5\end{array}$ \\
\hline Total de Despesas Operacionais........................... & $\underline{\mathrm{Crs}}$ & 300 & $30 \%$ & $\mathrm{Cr} \$$ & 400 & $26 \%$ & $\operatorname{cr} \$$ & 100 & $33 \%$ & 1,3 \\
\hline $\begin{array}{l}\text { Lucro Líquido Operacional ............................. } \\
\text { Outras Despesas } \\
\text { (e Despesas Financeiras) }\end{array}$ & $\mathrm{Cr} \&$ & $\begin{array}{l}300 \\
100 \\
\end{array}$ & $\begin{array}{l}30 \% \\
10 \\
\end{array}$ & Cr\$ & $\begin{array}{l}100 \\
10\end{array}$ & $\begin{array}{l}7 \% \\
1\end{array}$ & $(\mathrm{CrS} 2$ & 200) & $\begin{array}{l}(67 \%) \\
(90)\end{array}$ & 0,3 \\
\hline 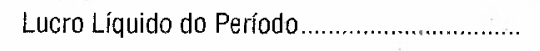 & $\operatorname{Cr} \$$ & 200 & $20 \%$ & $\mathrm{Cr} \$$ & 90 & $6 \%$ & $(\mathrm{Cr} \$ 1$ & 110) & $(55 \%)$ & 0,4 \\
\hline
\end{tabular}


minuíram para $3 \%$ em $19 \times 2$ ) e o decréscimo nas outras despesas (inclusive financeiras) em relação às vendas líquidas (de 10\% em 19x1 diminuíram para $1 \%$ em $19 \times 2$ ou, para sermos mais exatos, para $0,667 \%$ ), e embora as vendas líquidas tenham aumentado em $50 \%$ de um período para outro, isto não foi suficiente para contrabalançar os fatores que causaram a redução no lucro líquido, resultando, portanto, uma diminuição deste último, o qual é apenas 0,4 vezes lucro líquido de $19 \times 1$, em $19 \times 2$ (para sermos mais precisos, 0,45 vezes), com uma queda de $55 \%$.

Esse breve comentário sobre a análise vertical e horizontal do quadro 2 dá a perceber como ć, muitas vezes, um pouco complicada a matéria; daí resulta que freqüente são feitas afirmativas completamente errôneas nessa interpretação, pois não devemos esquecer que mudanças na percentagem da análise vertical são afetadas por alterações nos itcns que estão sendo medidos e na própria base - por exemplo, por modificações em um item de despesa e modificações nas vendas líquidas.

Além disso, as alterações nas percentagens ou índices da análise horizontal, sem levar em consideração a inflação, devem ainda ser interpretadas com o auxílio de informações suplementares. Assim, para ilustrar a questão, se as vendas líquidas aumentaram em $50 \%$, como ocorreu no caso da empresa Alfa, isso não significa necessariamente que seja satisfatório um aumento igual ou menor em qualquer item de despesa, pois há necessida-

de de determinar-se que parte da despesa em consideração é fixa e que porção da mesma é variável, sempre em relação às vendas.

Os administradores de empresas que trabalham no campo da administração contábil e financeira quase sempre encontram dificuldade em comunicar essas variáveis da análise da demonstração da conta de "Lucros e Perdas" a pessoas de outros setores de especialização a fim de que se possa por ela verificar os erros e acertos do passado e tomar decisóes para o futuro, na medida do possívcl, evitar a ocorrência dos erros. Torna-se, portanto, necessário encontrar uma forma melhor - e mais fácil para os não iniciados no campo da administração contábil e financeira - de mostrar as variações no lucro líquido de um período para outro.

\section{DEMONSTRAÇÃO DAS VARIACÓES NO LUCRO LIOUIDO DO PERIODO}

Um dos modos de solucionar a questão é apresentado no quadro 3.

Neste tipo de demonstração, percebese que os fatores causadores de aumento no lucro líquido em $19 \times 2$ - em comparação com $19 \times 1$ - foram o aumento de Cr\$500.000 nas vendas líquidas, a redução de $\mathrm{Cr} \$$ 50.000 nas despesas administrativas e a queda de Cr $\$ 90.000$ nas outras despesas (inclusive financeiras), totalizando Cr\$640.000. Por outro lado, os fatores que causaram diminuição nesse lucroforam o aumento de Cr\$ 600.000 no custo das mercadorias vendidas, a elevação de $\operatorname{Cr} \$ 100.000$ nas despesas de vendas e o acréscimo de $\mathrm{Cr} \$ 50.000$ nas despesas gerais, totalizando Cr\$ 750.000. Como a soma de fatores causadores de aumento atingiu somente $\mathrm{Cr} \$$ 640.000 - menos, portanto, que a soma dos fatores que trouxeram diminuição, isto é, Cr $\$ 750.000$-, houve uma queda no lucro líquido de um exercício para outro, de $\mathrm{Cr} \$ 110.000$.

Não há duvida de que o quadro 3 pode ser mais facilmente compreendido do que o quadro 2. Todavia, ainda assim, ele exige que se faça um breve co- 


\begin{tabular}{|l} 
QUADRO 3: Demonstração das Variações no Lucro Líquido do Período \\
(em milhares de cruzeiros)
\end{tabular}

3. Mais uma vez, chamamos a atenção do leitor para o problema de comunicações envolvido. Nem sempre as pessoas de outros campos de conhecimentos estão familiarizadas com os conceitos da administração contábil e financeira e há, portanto, necessidade de tornar as informações de que dispomos inteligiveis e acessiveis a elas. mentário como aquele acima sobre os dados que nem sempre - conforme a complexidade das informações disponíveis para a análise - é muito fácil compreender. ${ }^{3}$

Portanto, mais uma ve $z$, torna-se necessário o aperfeiçoamento na forma de apresentar as informações, de tal sorte que seja possível fazê-lo sem grande complexidade e com maior riqueza de pormenores.

\section{ANÁLISE EXPLICATIVA DAS VARIACŌES NO LUCRO LIQUIDO DO PERIODO}

Pode parecer redundância denominar uma demonstração "análise" e, além disso, "explicativa". Porém, o nome em si - algumas vezes - não importa muito. No caso importa mais o realce que pretendemos dar à diferença na forma de expor as informações, tal como se pode perceber pela comparação do quadro 4 com os anteriores.

As informaçōes constantes do quadro 4 e sua disposição realçam o fato de que, apesar de ter havido um aumento nas vendas, houve também um aumento mais que proporcional no custo das mercadorias vendidas e, com isso, uma tendência para redução no lucro líquido do período, dado que não era tão facilmente visível nas demonstrações anteriores.
Freqüentemente, é interessante ter, ao lado das diferenças nas quantias absolutas, os valores relativos dessas diferenças. Assim, por exemplo, a última tabela aponta que o lucro bruto sobre vendas diminuiu em $19 \times 2$ quando comparado ao de 19x1. Mas, quantas vezes ć ele menor em 19x2? quanto representava percentualmente em relação às vendas líquidas em 19x1 e quanto representa em $19 \times 2$ ? Para responder a essas e a outras questôes, o quadro 4 pode ser melhorado como mostramos a seguir.

\section{ANALISE EXPLICATIVA DAS VARIACOES NO LUCRO LIOUIDO DO PERIODO (EM VALORES RELATIVOS E ABSOLUTOS)}

O quadro 5 foi construído utilizandose basicamente as disposições constantes do quadro 4, mas com acréscimo dos dados fornecidos pela análise vertical e horizontal (quadro 2).

Apesar de aparentemente complexo, o quadro 5 tem a grande vantagem de ser bem mais completo que o quadro 2 e, além disso, de propiciar quase de relance a visão dos fatores que contribuíram para aumentar ou reduzir o lucro líquido do período em relação ao exercício anterior, tanto em valores absolutos, quanto relativos.

Deve ser tomado, na interpretação deste último quadro, cuidado especial 
no tocante às diferenças nas percentagens. Essas diferenças foram obtidas pela subtração de duas percentagens: da percentagem de um dado item em relação às vendas líquidas em 19x1 e da percentagem do mesmo itcm em relação às vendas líquidas em $19 \times 2$. Ora, como houve alteração na base do cálculo dessas percentagens - as vendas líquidas de $19 \times 2$ são $50 \%$ mais altas que as de $19 \times 1$ ou seja, 1,5 vezes - torna-se necessária muita cautela na interpretação, pois do contrário poder-se-á chegar a conclusões absurdas. Pode ser conveniente, por isso, conforme o caso, a eliminação da coluna referente às percentagens das vendas líquidas, ou, então, tão somente das linhas referentes às diferenças das percentagens.

A última coluna à direita do quadro 5 é, sem dúvida, necessária e contém informações preciosas. No caso da empresa Alfa, verifica-se por ela que as vendas líquidas de $19 \times 2$ representam 1,5 vezes as de $19 \times 1$ (aumento de $50 \%$ ) e que o custo das mercadorias vendidas em $19 \times 2$ é 2,5 vezes o de $19 \times 1$ (aumento de $150 \%$ ). Uma vez que a taxa de aumento no custo foi maior que a taxa de aumento nas vendas, a proporção do lucro bruto sobre vendas, que era de $60 \% \mathrm{em}$ $19 \times 1$, caiu para $33 \%$.

Esses e outros tipos de considerações podem e devem ser feitos, não nos esquecendo de que ao lado dos índices e percentagens temos também as quantias monetárias, que muito podem auxiliar na interpretação das proporções.

Quando for relativamente alta a taxa de inflação de um ano para outro, para não chegarmos a conclusões absurdas ou errôneas, é interessante não só fazer a análise na forma indicada no quadro 5, mas também deflacionar os dados do último período (ou inflacionar os dados do primeiro período), colocando as informações assim obtidas na forma constante do quadro. Dependendo da taxa de inflação, do tipo e da natureza da empresa etc., são muitas vezes enormes as diferenças que aparecem, quando trabalhamos com dados históricos (não ajustados), em comparação com dados ajustados.

No caso da empresa Alfa, para ilustrar a questão, supondo-se que o índice

\section{QUADRO 4: \\ Análise Explicativa das Variações no Lucro Líquido do Período (em milhares de cruzeiros)}

\section{O LUCRO LLOUIDO FOI DIMINUÍDO POR:}

I- Diminuição no Lucro Bruto sobre Vendas, em decarrência de:

a. Aumento no Custo das Mercadorias Vendidas:

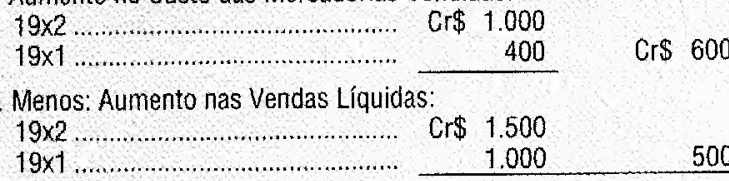

Diminuição no Lucro Bruto sobre Vendas

Cr\$ 100

II - Aumento nas Despesas de Vendas:

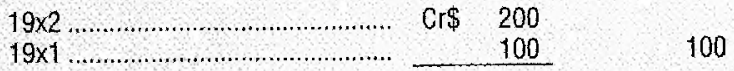

III- Aumento nas Despesas Gerais:

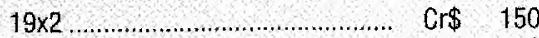

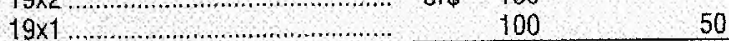

Total de Fatores que Diminuiram o Lucro Liquido Cr\$250

O LUCRO LIQQUIDO FOI AUMENTADO POR:

1. Diminuição nas Despesas Administrativas:

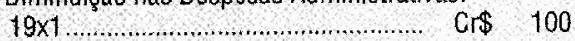

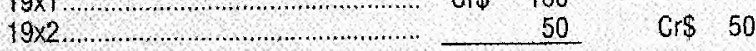

1I-Diminuição nas Outras Despesas (e Despesas Financeiras)

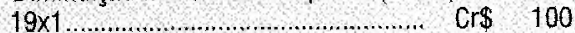

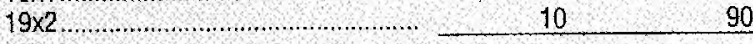

Total de Fatores que Aumentaram o Lucro Liquido $\operatorname{cr} \$ 140$

RESULTOU DISSO UMA DIMINUIÇÃO NO LUCRO LÍQUIDO DE $\operatorname{cr} \$ 110$

de custo de vida - ou qualquer outro índice que melhor reflita a taxa de inflação - em 19x1 seja 439 (em relação a um ano-base qualquer) e $607 \mathrm{em} \mathrm{19 \times 2,} \mathrm{resul-}$ tará que as vendas do ano de $19 \times 2$, quando expressas ou convertidas em termos do nível de preços de $19 \times 1$, serão de apenas $\mathrm{Cr} \$ 1.084 .800 .^{4}$

\section{RESUMO E CONCLUSÕES}

Verificamos que análise vertical e horizontal clássica da demonstração da conta de "Lucros e Perdas", tal como apresentada no quadro 2 , não é de muito fácil compreensão, principalmente por parte dos leigos, os quais, no entanto, necessitam muitas vezes saber por que houve variação no lucro líquido do período de um exercício contábil para outro.

Vimos que a explicação para essa variação pode ser bem melhor entendida se feita na forma indicada no quadro 3 ,
4. Essa quantia foi obtida mediante o seguinte cálculo:

vendas Custo de

$19 \times 2$ Cr\$ $1.500 .000 \quad 627$

Portanto, o fator de conversão é: 439

$\overline{627}=0,7232$

Logo:

Cr\$1.500.000 x 0,7232= $\mathrm{Cr} \$ 1.084 .800$
$19 \times 1$ Cr\$ $1000.000 \quad 439$ 


\section{QUADR0 5: Análise Explicativa das Variacões no Lucro do Período (Valores Relativos e Absolutos) (milhares de cruzeiros)}

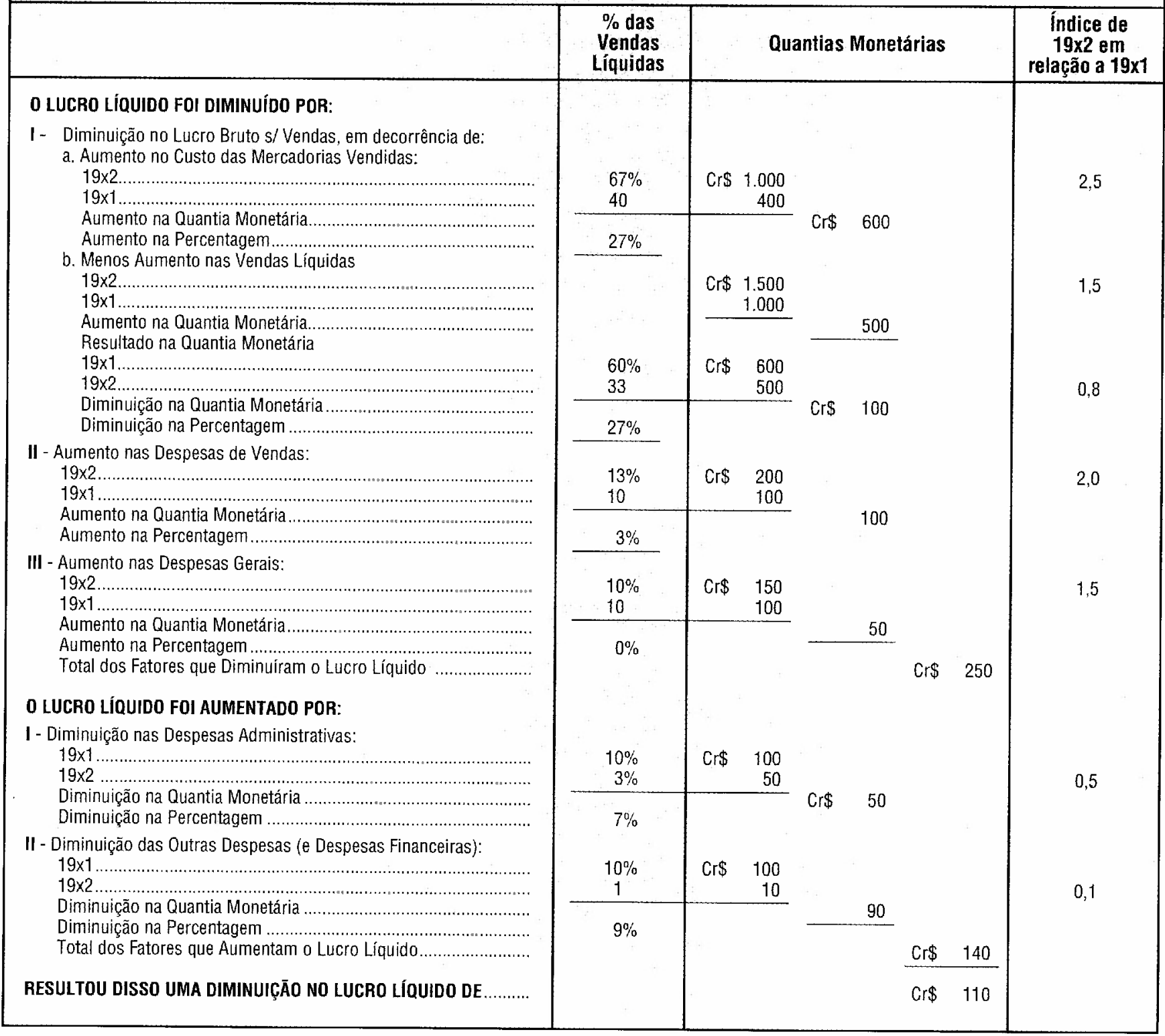

o qual, por sua vez, pode tornar-se mais informativo se elaborado de acordo com o mostrado no quadro 4.

Todavia, a análise das variações no lucro líquido do período, obtida nesse último quadro, é fcita tão somente em termos absolutos; faltando as quantias relativas, não há possibilidade de se ter noção exata do que ocorreu. Assim, empregando-se basicamente a disposição das informações constantes do quadro 4 e acrescentando-se-lhes as importâncias relativas fornecidas pela análise vertical e horizontal, chegamos ao quadro 5 .
Vimos também alguns cuidados a serem levados em consideração nos dados percentuais e a sugestão - de acordo com a situação específica da empresa que for utilizar os conceitos examinados neste artigo - de eliminação de uma coluna ou de algumas linhas desse último quadro.

Havendo uma taxa inflacionária relativamente elevada de um exercício para outro, sugerimos que, após a obtenção do quadro $5 \mathrm{em}$ dados históricos, sejam as quantias do último período deflacionadas ao nível do poder de compra do 
exercício anterior e depois dispostas no formato indicado pelo quadro, a fim de poder-se perceber as deformações decorrentẹs da inflação. Exemplificando o problema, notamos que no caso da empresa Alfa as vendas de $19 \times 2$, quando convertidas em termos do nível de preços de $19 \times 1$, eram quase idênticas à quantia monetária das vendas desse período e, no entanto, aparentemente, tinham aumentado em $50 \%$.

Em resumo, portanto, foi possível notar que a variação no lucro líquido do período pode ser atribuída à modificação no lucro bruto sobre vendas, a alterações nas despesas operacionais, ou nas receitas (inclusive financeiras) e outras despesas (inclusive financeiras).

Naturalmente, as modificações no lucro bruto sobre vendas podem ser provenientes de alterações no volume físico de unidades vendidas, no preço unitário de venda e no custo unitário das mercadorias vendidas, o que em si mereceria estudo e explicação bem minuciosos.

As despesas operacionais podem ser também esmiuçadas e depois analisadas vertical e horizontalmente, porém, para o seu perfeito controle, o melhor é ter um processo orçamentário bem feito e um sistema de registros de "contabilidade por responsabilidade" ${ }^{\prime \prime}$, uma vez que as alterações nas despesas operacionais entre dois exercícios podem resultar de numerosas causas, como, por exemplo, de mudanças nos métodos de operação, no volume físico de unidades transacionadas, nas diretrizes da empresa, na eficiência administrativas arbitrárias que aumentem ou diminuam as despesas operacionais, como salário, propaganda ou investimento em ativo fixo etc.

Apesar das ponderações feitas nos dois últimos parágrafos, acreditamos que é de valia ao administrador de empresas a análise das variações do lucro líquido, pois ela será um primeiro passo no sentido de descobrir erros e acertos do passado e de tomar providências no sentido de evitar no futuro, sendo possível, os erros cometidos, uma vez que será depois da análise tal como exposta neste artigo, que ele poderá chegar à análise cuidadosa do lucro bruto sobre vendas etc.

Não é, porém, descabida uma última palavra de precaução a ser levada em consideração neste e em outros tipos de análises: "E tão difícil interpretar percentagens, quando não estão acompanhadas das quantias absolutas, como compreender o significado das quantias, sem relacioná-las com um padrão de comparaçāo. Tem pouco significado verificar que o lucro líquido para $19 \times 2$ é $10 \%$ maior que o lucro líquido de 19x1, se em ambos anos ele for totalmente inadequado em relação aos ativos investidos na empresa. Como alguém com perspicácia observou: 'O que se deposita nos bancos é dinheiro e não percentagens'...". ${ }^{6}$

\section{BIBLIOGRAFIA SUPLEMENTAR}

4. FINNEY, H. A., MILLER, H. E. Principles of accounting, intermediate $6^{a}$ ed. Englewood Cliffs: Prentice Hall, 1965.

: HOLMES, A.W., MAYNARD, G. P., EDWARDS, J. D., MEIER, R.A. Intermediate accounting. $3^{\text {a }}$ ed. Homewood, Illinois: Richard D. Irwin, 1958.

* KARRENBROCK, W. E., SIMONS, H, Intermediate accounting, comprehensive volume. $3^{\mathrm{a}}$ ed. Cincinnatti: South-Western, 1958.

* KENNEDY, R. D., MCMULLEN, S. Y. Financial statements, form, analysis and interpretation. $4^{a}$ ed. Homewood, Illinois: Richard Irwin, 1962.

MYER, J. N. Financial statement analysis. Principles and Techniques. $3^{\mathrm{a}}$ ed. Englewood Cliffs: Prentice Hall, 1961.

5. "Contabilidade por responsabilidade" é tradução da expressão inglesa responsability accounting, que se refere a um sistema que revele não apenas o que ocorre em uma empresa, mas também, quem é responsável por isso, Naturalmente, a fim de poder funcionar de maneira adequada, 0 sistema deve ser reflexo fiel da organização da estrutura, a qual, por sua vez, deve ter sido concebida em bases científicas e reais.

6. BLACK, H. J., CHAMPION, J. E. Accounting in Business Decisions, Theory, Method and Use. Englewood Cliffs: Prentice-Hall, Inc., 1961, p. 273 